\title{
Outcomes of COVID-19 patients treated with continuous positive airway pressure outside the intensive care unit
}

\section{Rosanna Vaschetto (10 1,2,18, Francesco Barone-Adesi ${ }^{2,18}$, Fabrizio Racca ${ }^{3}$, Claudio Pissaia ${ }^{4}$, Carlo Maestrone ${ }^{5}$, Davide Colombo $\mathbb{1}^{6}$, Carlo Olivieri ${ }^{7}$, Nello De Vita², Erminio Santangelo (102 ${ }^{2}$, Lorenza Scotti ${ }^{2}$, Luigi Castello ${ }^{2,8}$, Tiziana Cena (10), Martina Taverna ${ }^{3}$, Luca Grillenzoni ${ }^{9}$, Maria Adele Moschella ${ }^{10}$, Gianluca Airoldi ${ }^{11}$, Silvio Borrè ${ }^{12}$, Francesco Mojoli ${ }^{13}$, Francesco Della Corte ${ }^{1,2}$, Marta Baggiani $^{2}$, Sara Baino ${ }^{2}$, Piero Balbo ${ }^{14}$, Simona Bazzano ${ }^{1}$, Valeria Bonato ${ }^{3}$, Sara Carbonati ${ }^{2}$, Federico Crimaldi ${ }^{2}$, Veronica Daffara², Luca De Col ${ }^{4}$, Matteo Maestrone ${ }^{2}$, Mario Malerba ${ }^{2,15}$, Federica Moroni ${ }^{2}$, Raffaella Perucca $^{1}$, Mario Pirisi ${ }^{2,16}$, Valentina Rondi², Daniela Rosalba², Letizia Vanni², Francesca Vigone ${ }^{2}$, Paolo Navalesi (1) $^{17,19}$ and Gianmaria Cammarota ${ }^{1,19}$ for the COVID-19 Eastern Piedmont Network}

\section{ABSTRACT}

Aim: We aimed to characterise a large population of coronavirus disease 2019 (COVID-19) patients with moderate-to-severe hypoxaemic acute respiratory failure (ARF) receiving continuous positive airway pressure (CPAP) outside the intensive care unit (ICU), and to ascertain whether the duration of CPAP application increased the risk of mortality for patients requiring intubation.

Methods: In this retrospective, multicentre cohort study, we included adult COVID-19 patients, treated with CPAP outside ICU for hypoxaemic ARF from 1 March to 15 April, 2020. We collected demographic and clinical data, including CPAP therapeutic goal, hospital length of stay and 60-day in-hospital mortality.

Results: The study included 537 patients with a median (interquartile range (IQR) age of 69 (60-76) years. 391 (73\%) were male. According to the pre-defined CPAP therapeutic goal, 397 (74\%) patients were included in the full treatment subgroup, and $140(26 \%)$ in the do not intubate (DNI) subgroup. Median (IQR) CPAP duration was 4 (1-8) days, while hospital length of stay was 16 (9-27) days. 60-day in-hospital mortality was $34 \%$ (95\% CI $0.304-0.384 \%)$ overall, and $21 \%$ (95\% CI $0.169-0.249 \%)$ and $73 \%$ (95\% CI 0.648-0.787\%) for full treatment and DNI subgroups, respectively. In the full treatment subgroup, inhospital mortality was $42 \%$ (95\% CI $0.345-0.488 \%$ ) for 180 (45\%) CPAP failures requiring intubation, and $2 \%$ (95\% CI $0.008-0.035 \%)$ for the remaining 217 (55\%) patients who succeeded. Delaying intubation was associated with increased mortality (hazard ratio 1.093, 95\% CI 1.010-1.184).

Conclusions: We described a large population of COVID-19 patients treated with CPAP outside ICU. Intubation delay represents a risk factor for mortality. Further investigation is needed for early identification of CPAP failures.

@ERSpublications

This study describes characteristics and in-hospital mortality of the largest population of COVID-19 patients treated with CPAP outside ICU. Treatment duration for patients failing CPAP prior to intubation represents a risk factor for mortality. https://bit.ly/3orolzd

Cite this article as: Vaschetto R, Barone-Adesi F, Racca F, et al. Outcomes of COVID-19 patients treated with continuous positive airway pressure outside the intensive care unit. ERJ Open Res 2021; 7: 00541-2020 [https://doi.org/10.1183/23120541.00541-2020].

This article has supplementary material available from openres.ersjournals.com

Received: 30 July 2020 | Accepted after revision: 16 Oct 2020

Copyright $\odot$ ERS 2021. This article is open access and distributed under the terms of the Creative Commons Attribution Non-Commercial Licence 4.0. 


\section{Introduction}

Noninvasive ventilation (NIV) administered as bilevel positive airway pressure (BiPAP) or continuous positive airway pressure (CPAP) is commonly used in various critical care settings across a variety of aetiologies of acute respiratory failure (ARF). For hypercapnic ARF, mainly consequent to COPD exacerbation, BiPAP can be used at an early stage to prevent intubation, at a later stage as an alternative to first-line endotracheal intubation, or as a means to facilitate weaning [1]. For hypoxaemic ARF, recommendations strongly support the use of both BiPAP and CPAP in patients with episodes of cardiogenic pulmonary oedema [1,2], while fewer data suggest their use in immunosuppressed [1,3] and in post-operative $[1,4]$ patients. In patients with de novo hypoxaemic ARF, evidence and recommendations on the use of NIV are still to be determined [1]. Moreover, the application of NIV in patients with acute respiratory distress syndrome (ARDS) complicating viral pneumonia is controversial [5].

During the coronavirus disease 2019 (COVID-19) pandemic, Piedmont, together with Lombardy, Emilia-Romagna and Veneto, was one of the most affected Italian regions. Due to the exceptional demand on intensive care unit (ICU) resources, hospitals increased the number of ICU beds and converted many general wards in respiratory intermediate care units (RICUs) to treat patients with severe pneumonia and ARDS needing respiratory support and monitoring. Indeed, NIV in patients with different therapeutic indications, i.e. full treatment and do not intubate (DNI) [6], has been shown to be successfully applicable outside the ICU $[7,8]$, when appropriate monitored settings and trained personnel are employed.

Data on NIV during the COVID-19 pandemic, so far, consider predominantly patients admitted to the ICU [9-13]. The rate of patients receiving NIV at ICU admission ranges from $11 \%$, as reported by an Italian multicentre investigation [10], to 56\%, according to a Chinese single-centre study [11]. Exposure to noninvasive forms of respiratory support may have been even more diffuse outside ICU, although only data from two monocentre studies are presently available, accounting overall for 40 patients; 38 treated with CPAP [14] and two with NIV or high-flow oxygen therapy [15].

We designed this retrospective multicentre study to describe the clinical characteristics of patients with laboratory-confirmed COVID-19 treated with CPAP outside ICU, to assess 60-day in-hospital mortality and hospital length of stay (LOS), and to ascertain whether the duration of CPAP application prior to CPAP failure affects outcome in patients requiring endotracheal intubation.

\section{Methods}

\section{Study design}

This is a multicentre, retrospective observational study performed in six hospitals in the Eastern Piedmont area of Northern Italy. All the participating centres obtained ethics committee approval. More details on study design and ethics approval are provided in the supplementary material.

\section{Patient enrolment and data collection}

All patients were admitted to one of the participating hospitals from March 1 to April 15, 2020 with hypoxaemic ARF secondary to confirmed severe acute respiratory syndrome coronavirus 2 . Inclusion criteria were 1$)$ age $\geqslant 18$ years; 2$)$ respiratory distress and partial pressure of arterial oxygen $\left(P_{\mathrm{aO}_{2}}\right)$ to inspiratory oxygen fraction $\left(F_{\mathrm{iO}_{2}}\right)$ ratio $<200 \mathrm{mmHg}$ during Venturi mask oxygen therapy; and 3) CPAP initiation outside ICU. Patients who received post-extubation CPAP were excluded.

\footnotetext{
Affiliations: ${ }^{1}$ Azienda Ospedaliero Universitaria "Maggiore della Carità", Anestesia e Terapia Intensiva Novara, Italy. ${ }^{2}$ Università del Piemonte Orientale, Dipartimento di Medicina Traslazionale, Novara, Italy. ${ }^{3}$ Azienda Ospedaliera SS. Antonio e Biagio e Cesare Arrigo, Department of Anaesthesia and Intensive Care, Alessandria, Italy, EU. ${ }^{4}$ Ospedale degli Infermi, Dipartimento di Anestesia e Terapia Intensiva, Ponderano, Biella, Italy. ${ }^{5}$ Presidio Ospedaliero Domodossola e Verbania, Anestesia Rianimazione ASL VCO, Direzione dipartimento chirurgico, Largo Caduti Lager Nazisti, Domodossola, Italy. ${ }^{6}$ Ospedale Ss. Trinità, Department of Anaesthesia and Critical Care, Borgomanero, Italy. ${ }^{7}$ Azienda Ospedaliera Sant'Andrea, Department of Anaesthesia and Critical Care, Vercelli, Italy. ${ }^{8}$ Azienda Ospedaliero Universitaria "Maggiore della Carità", Medicina d'Urgenza, Novara, Italy. ${ }^{9}$ Ospedale degli Infermi, Medicina D'Urgenza, Ponderano, Biella, Italy. ${ }^{10}$ Presidio Ospedaliero Domodossola, Medicina Interna ASL VCO, Largo Caduti Lager Nazisti, Domodossola, Italy. ${ }^{11}$ Ospedale Ss. Trinità, Medicina Interna, Borgomanero, Italy. ${ }^{12}$ Azienda Ospedaliera Sant'Andrea, Malattie Infettive, Vercelli, Italy. ${ }^{13}$ University of Pavia, Fondazione IRCCS Policlinico San Matteo, Anaesthesia and Intensive Care, Pavia, Italy. ${ }^{14}$ Azienda Ospedaliero Universitaria "Maggiore della Carità", Pneumologia, Novara, Italy. ${ }^{15}$ Azienda Ospedaliera Sant'Andrea, Pneumologia, Vercelli, Italy. ${ }^{16}$ Azienda Ospedaliero Universitaria "Maggiore della Carità", Clinica Medica, Novara, Italy. ${ }^{17}$ Istituto di Anestesia e Rianimazione, Azienda Ospedale-Università di Padova, Dipartimento di Medicina - DIMED - Università di Padova, Padua, Italy. ${ }^{18}$ These authors contributed equally. ${ }^{19}$ These authors contributed equally.
}

Correspondence: Rosanna Vaschetto, Università del Piemonte Orientale, Dipartimento di Medicina Traslazionale, via Solaroli 17, 28100, Novara, Italy. E-mail: rosanna.vaschettodmed.uniupo.it 
Patients were classified according to a pre-defined CPAP therapeutic goal applied by the medical team, in two subgroups [6]: 1) full treatment, i.e. patients scheduled to receive intubation in cases of CPAP failure; and 2) DNI, when CPAP was the ceiling of treatment. In cases where the patient changed the therapeutic goal during hospital stay, the last CPAP goal was considered. The therapeutic goal of CPAP was collegially discussed within the multidisciplinary teams, with the patients and their families, taking into account comorbidities [16], quality of life and patient wishes. Possible discrepancies between patients and relatives were solved through additional discussions between patient, relatives and the medical team.

Demographic characteristics, body mass index (BMI), blood sample exams performed at hospital entry (white blood cell count, lymphocyte count, creatinine, alanine transaminase, aspartate transaminase, lactate dehydrogenase, C-reactive protein, D-dimer, ferritin), arterial blood gas (ABG) values obtained prior to CPAP initiation and 2-24 h after and coexisting comorbidities were recorded. Charlson comorbidity index (CCI) [17] was computed on the first day of hospital admission. This index contemplates 17 categories of comorbidity recorded via anamnesis. Age is not included as a comorbidity in the CCI version adopted. Finally, we collected data about clinical outcomes, such as duration of CPAP use, hospital LOS, intubation and hospital mortality. The outcomes were censored on May 15, 2020 for patients still in the hospital on that day $(\mathrm{n}=32)$.

\section{CPAP and RICU organisation}

Details on CPAP setting, schedule, RICU organisation and criteria for intubation are described in the supplementary material.

\section{Statistical analysis}

Descriptive statistics are used to summarise the main demographic characteristics and the results of laboratory findings of all patients included in the study. Categorical variables are reported as absolute frequencies and percentages, while numerical variables as median and interquartile range (IQR). The frequency and percentage of missing values for all variables are also reported. The Mann-Whitney U-test is used to assess the difference between two independent samples, and the Wilcoxon signed-rank test for repeated measurements. Chi-squared is used for testing relationships of categorical variables.

Curves of cumulative incidence of in-hospital mortality are drawn to describe mortality along 60 days, either overall and stratified for treatment goal, and in the full treatment subgroup separately for patients succeeding CPAP or receiving intubation.

In order to avoid immortal time bias, in the survival analysis of patients receiving intubation, the observation period started at the day of intubation. In the other analyses, the observation period started at the day of CPAP initiation. Since discharge must be considered an informative censoring [18], cumulative incidence was calculated using methods accounting for competing risk. To evaluate the cumulative incidence of in-hospital mortality for patients not undergoing intubation, all full-treatment subjects are considered, and intubation is treated as a competing event allowing the contribution of the time spent by intubated patients on CPAP to be accounted for. Gray's test is used to assess the difference between cumulative incidence functions. The Fine and Gray multivariate competing risk model is adopted to calculate the subdistribution hazard ratios and the corresponding 95\% confidence intervals for the association between CPAP duration and in-hospital mortality risk in intubated patients, considering discharge as competing event. In the main analyses, missing data are managed by listwise deletion. In addition, we performed a secondary analysis using multiple imputation to evaluate the impact of missing values on the association estimates. Missing imputation is performed using the expectation-maximisation algorithm (500 imputations) and considering the "missing at random" mechanism. More details about the model are provided in the supplementary material.

All hypothesis tests are two-tailed and a significance level of 0.05 is considered. All statistical analysis was performed using Stata (Stata Statistical Software: release 15; StataCorp, College Station, TX, USA), SAS (version 9.4; SAS Institute, Cary, NC, USA) and R (version 3.5.1; http://R-project.org).

\section{Results}

From March 1 to April 15, a total of 2845 patients with confirmed COVID-19 were admitted to the six hospitals of the Eastern Piedmont (supplementary figure 1S). Of these, 326 (11\%) patients were treated in ICU; $31(1 \%)$ and 295 (10\%) with noninvasive and invasive mechanical ventilation, respectively. CPAP was applied to 537 (22\%) patients in RICU.

Table 1 shows the demographic and clinical patients' characteristics. The number of observations for each variable is displayed in supplementary table 1S. The median (IQR) age was 69 (60-76) years and BMI was 28 $(25-31) \mathrm{kg} \cdot \mathrm{m}^{-2} .391(73 \%)$ were male. Laboratory values at hospital admission are also summarised in table 1. 


\begin{tabular}{|c|c|}
\hline Patients & 537 \\
\hline Age years & $69(60-76)$ \\
\hline Male & $391(73)$ \\
\hline BMI $\mathrm{kg} \cdot \mathrm{m}^{-2}$ & $28(25-31)$ \\
\hline White blood cell count $\times 10^{3}$ cells $\mu \mathrm{L}^{-1}$ & $6.9(5.1-9.5)$ \\
\hline Lymphocyte count $\times 10^{3}$ cells $\mu \mathrm{L}^{-1}$ & $0.8(0.6-1.1)$ \\
\hline Creatinine $\mathrm{mg} \cdot \mathrm{dL}^{-1}$ & $1.0(0.8-1.3)$ \\
\hline Aspartate-aminotransferase $\mathrm{U} \cdot \mathrm{L}^{-1}$ & $41(29-59)$ \\
\hline Alanine-aminotransferase $\mathrm{U} \cdot \mathrm{L}^{-1}$ & $31(22-50)$ \\
\hline C-reactive protein $\mathrm{mg} \cdot \mathrm{dL}^{-1}$ & $11(6-17)$ \\
\hline Ferritin $\mathrm{ng} \cdot \mathrm{mL}^{-1}$ & $1053(565-1643)$ \\
\hline Lactate dehydrogenase $\mathrm{U} \cdot \mathrm{L}^{-1}$ & $560(410-786)$ \\
\hline D-dimer $\mu \mathrm{gFEU} \cdot \mathrm{L}^{-1}$ & $954(526-1874)$ \\
\hline Charlson Comorbidity Index & $1(0-2)$ \\
\hline Chronic arterial hypertension & $278(52)$ \\
\hline Diabetes & $138(26)$ \\
\hline Ischaemic heart disease & $66(12)$ \\
\hline CPAP days & $4(1-8)$ \\
\hline Hospital length of stay days & $16(9-27)$ \\
\hline $\begin{array}{l}\text { Data are presented as } n \text {, median } \\
\text { fibrinogen-equivalent unit. }\end{array}$ & ass index; FEU: \\
\hline
\end{tabular}

Median (IQR) white blood cell count was $6.9(5.1-9.5) \times 10^{3}$ cells $\mu \mathrm{L}^{-1}$, with lymphopenia $0.8(0.6-1.1) \times 10^{3}$ cells $\mu \mathrm{L}^{-1}$. Median values of creatinine, aspartate-aminotransferase and alanine-aminotransferase were in the normal range, while C-reactive protein, ferritin, lactate dehydfrogenase and D-dimer were all above the normal range. Median (IQR) CCI value was $1(0-2)$; chronic arterial hypertension was present in 278 (52\%) patients, diabetes in $138(26 \%)$ patients and ischaemic heart disease in $66(12 \%)$ patients.

The most common interface was the helmet, in 399 (74\%) patients, while face masks were used in 123 (23\%) patients; 15 (3\%) patients alternated both interfaces. Median (IQR) CPAP duration was 4 (1-8) days. Overall cumulative 60-day in-hospital mortality was 34\% (cumulative incidence 0.344 , 95\% CI 0.304-0.384), as depicted in figure 1a, while median (IQR) hospital LOS was 16 (9-27) days.

Demographic and clinical patients' characteristics stratified by $P_{\mathrm{aO}} / F_{\mathrm{iO}}$ performed $2-24 \mathrm{~h}$ after initiation of CPAP and application of the interface are provided in supplementary tables $2 \mathrm{~S}$ and $3 \mathrm{~S}$, respectively. Overall cumulative 60-day in-hospital mortality stratified according to $P_{\mathrm{aO}_{2}} / F_{\mathrm{iO}_{2}}$ and interface applied is depicted in supplementary figure $2 \mathrm{~S}$. As expected, mortality seemed to increase in patients with lower $P_{\mathrm{aO}_{2}} / F_{\mathrm{iO}_{2}}$ ratio, while it did not differ between patients treated using helmet (cumulative incidence 0.315, $95 \%$ CI $0.270-0.361$ ) or face mask (cumulative incidence $0.407,95 \%$ CI $0.320-0.493$; $\mathrm{p}=0.094$ ).
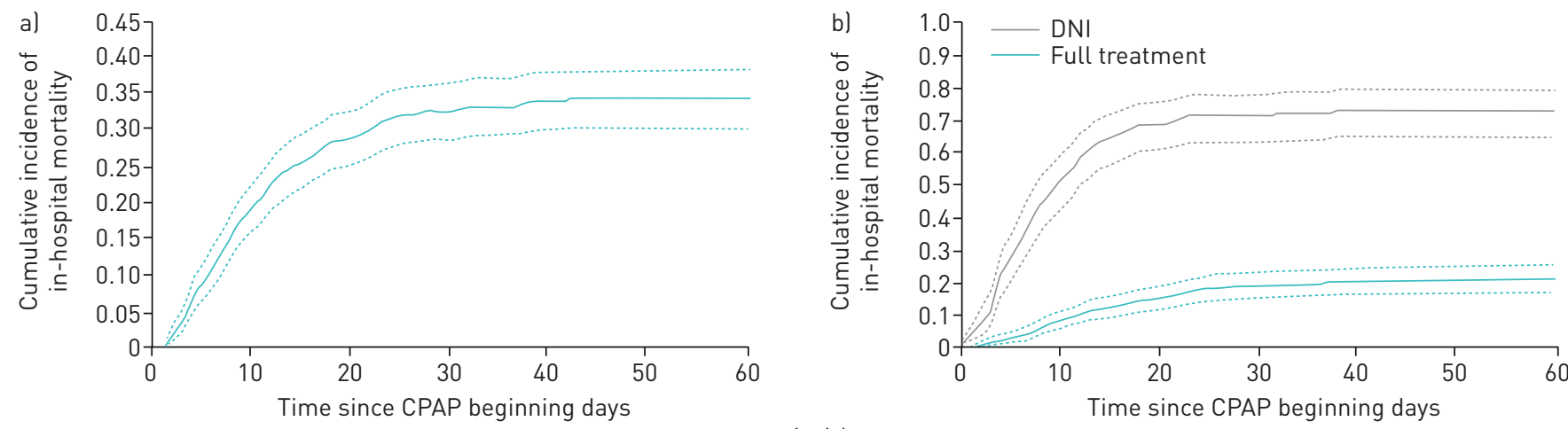

At risk $n$ 
When dividing patients according to the therapeutic goal (table 2), patients in the full treatment subgroup were younger (median (IQR) 66 (57-72) years) compared to DNI (median (IQR) 79 (72-84) years). The DNI subgroup had higher D-dimer values than full treatment patients (median (IQR) 1351 (637-3518) $\mu \mathrm{g}$ fibrinogen-equivalent units $(\mathrm{FEU}) \cdot \mathrm{L}^{-1}$ versus $\left.897(496-1665) \mu \mathrm{gFEU} \cdot \mathrm{L}^{-1} ; \mathrm{p}=0.02\right)$, and greater CCI (median (IQR) $2(1-3)$ versus $0(0-1) ; \mathrm{p}<0.0001)$. The number of observations for each variable is displayed in supplementary table $4 \mathrm{~S}$.

Supplementary table $5 \mathrm{~S}$ shows $\mathrm{ABG}$ and supplementary table $6 \mathrm{~S}$ shows the number of observations for each variable. While the first $\mathrm{ABG}$ measurements indicated in supplementary table $5 \mathrm{~S}$ were performed a median 1 day (IQR 0-3 days) after hospital admission, the second was performed 2-24 h after CPAP initiation.

Before starting CPAP, patients presented a median (IQR) $P_{\mathrm{aO}_{2}} / F_{\mathrm{iO}_{2}}$ ratio of $108(71-157) \mathrm{mmHg}$ and a respiratory rate of $27(22-32)$ breaths $\mathrm{min}^{-1}$. Soon after $\mathrm{CPAP}, P_{\mathrm{aO}_{2}} / F_{\mathrm{iO}_{2}}$ increased to 157 (109-255) $\mathrm{mmHg}$ and respiratory rate decreased to $24(20-28)$ breaths $\mathrm{min}^{-1}$ with CPAP of $10(10-12) \mathrm{cmH}_{2} \mathrm{O}$ and $F_{\mathrm{iO}_{2}}$ of $50 \%$ (50-60\%). Median CPAP duration was 4 days for both subgroups, while hospital LOS was 19 (11-30) days for full treatment and 11 (6-20) days for the DNI subgroup.

Figure $1 \mathrm{~b}$ depicts 60-day in-hospital mortality for full treatment (21\% (cumulative incidence $0.208,95 \%$ CI 0.169-0.249)) and DNI (73\% (cumulative incidence 0.731, 95\% CI 0.648-0.787); p<0.0001). Within the full treatment subgroup, 60-day in-hospital mortality was $42 \%$ (cumulative incidence $0.418,95 \% \mathrm{CI}$ $0.345-0.488$ ) for patients receiving intubation (figure 2) and $2 \%$ (cumulative incidence $0.018,95 \% \mathrm{CI}$ 0.008-0.035) for patients with successful CPAP (supplementary figure 3S).

Median (IQR) CPAP duration was 2 (1-3) days in patients who survived and 3 (1-5) days in patients who died $(\mathrm{p}=0.061)$. Table 3 shows that duration of CPAP application was an independent predictor of mortality for patients requiring intubation. The model, adjusting for age, sex, comorbidities, lactate dehydrogenase, C-reactive protein values and lymphocyte count, indicates a 9.4\% (hazard ratio (HR) 1.094, 95\% CI 1.010-1.184) increase in the risk of death for each day of treatment. The association between duration of CPAP and mortality does not substantially change in the secondary analysis using multiple imputation (HR 1.060, 95\% CI 1.001-1.121), as presented in supplementary table 7S. 60-day in-hospital mortality was significantly higher in patients subjected to CPAP for $>3$ days (cumulative incidence $0.510,95 \%$ CI $0.393-0.615$ ) as compared to those receiving CPAP for $\leqslant 3$ days (cumulative incidence $0.350,95 \%$ CI $0.259-0.441$ ), as shown in supplementary figure $4 \mathrm{~S}$.

\section{TABLE 2 General characteristics of patients stratified according to noninvasive continuous positive airway pressure (CPAP) therapeutic goal}

\begin{tabular}{|c|c|c|c|}
\hline & Full treatment & Do not intubate & p-value \\
\hline Patients & 397 & 140 & \\
\hline Age years & $66(57-72)$ & 79 (72-84) & $<0.0001$ \\
\hline Male & $293(74)$ & $98(70)$ & 0.22 \\
\hline BMI $\mathbf{k g} \cdot \mathrm{m}^{-2}$ & $28(25-31)$ & $28(25-31)$ & 0.74 \\
\hline White blood cell count $\times 10^{3}$ cells $\mu \mathrm{L}^{-1}$ & $6.8(5.1-9.1)$ & $7.1(5.0-10.6)$ & 0.47 \\
\hline Lymphocyte count $\times 10^{3}$ cells $\cdot \mu \mathrm{L}^{-1}$ & $0.8(0.6-1.1)$ & $0.7(0.5-1.1)$ & 0.04 \\
\hline Creatinine $\mathrm{mg} \cdot \mathrm{dL}^{-1}$ & $0.9(0.8-1.2)$ & $1.2(0.9-1.5)$ & $<0.0001$ \\
\hline Aspartate-aminotransferase $\mathrm{U} \cdot \mathrm{L}^{-1}$ & $42(31-59)$ & $39(26-60)$ & 0.36 \\
\hline Alanine-aminotransferase $\mathrm{U} \cdot \mathrm{L}^{-1}$ & $34(24-53)$ & 25 (19-39) & $<0.0001$ \\
\hline C-reactive protein $\mathrm{mg} \cdot \mathrm{dL}^{-1}$ & $11(6-17)$ & $12(7-18)$ & 0.26 \\
\hline Ferritin $\mathrm{ng} \cdot \mathrm{mL}^{-1}$ & $1068(600-1674)$ & $817(411-1389)$ & 0.08 \\
\hline Lactate dehydrogenase U. $\mathrm{L}^{-1}$ & $575(415-786)$ & $538(393-760)$ & 0.47 \\
\hline D-dimer $\mu \mathrm{gFEU} \cdot \mathrm{L}^{-1}$ & $897(496-1665)$ & 1351 (637-3518) & 0.02 \\
\hline Charlson Comorbidity Index & $0(0-1)$ & $2(1-3)$ & $<0.0001$ \\
\hline Chronic arterial hypertension & $199(50)$ & $79(56)$ & 0.12 \\
\hline Diabetes & $94(24)$ & $44(31)$ & 0.047 \\
\hline Ischaemic heart disease & 37 (9) & $29(21)$ & 0.001 \\
\hline CPAP days & $4(2-9)$ & $4(1-8)$ & 0.33 \\
\hline Hospital LOS days & $19(11-30)$ & $11(6-20)$ & $<0.0001$ \\
\hline \multicolumn{4}{|c|}{$\begin{array}{l}\text { Data are presented as } n \text {, median (interquartile range) or } n(\%) \text {, unless otherwise stated. BMI: body mass } \\
\text { index; FEU: fibrinogen-equivalent unit; LOS: length of stay. } p \text {-values were calculated using Mann-Whitney } \\
\text { U-test or Chi-squared test, as appropriate. }\end{array}$} \\
\hline
\end{tabular}


FIGURE 2 Cumulative incidence of in-hospital mortality in patients requiring invasive mechanical ventilation. Data are presented with $95 \% \mathrm{Cl}$. ETI: endotracheal intubation.

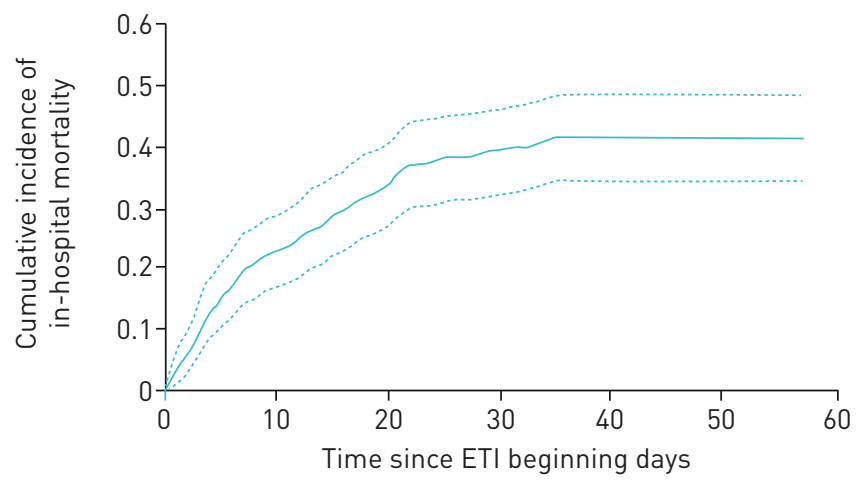

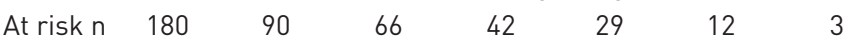

\section{Discussion}

This multicentre retrospective observational study on 537 patients with hypoxaemic ARF secondary to laboratory-confirmed COVID-19 infection shows that CPAP applied to different therapeutic goals, i.e. candidate for intubation in the case of CPAP failure, and do not intubate, in which CPAP is considered the ceiling of treatment, is feasible outside ICU. Treatment duration for patients failing CPAP prior to intubation represents a risk factor for mortality.

CPAP can be delivered both in ICU and outside ICU. Grasselli et al. [10] found that 11\% of patients entering ICU needed NIV, while early data from China revealed higher percentages, i.e. 41.7\% [13], 43.3\% [19], 56\% [11] and 62\% [15]. In keeping with data from Grasselli et al. [10], CPAP was delivered to 31 (9.5\%) out of 326 patients entering the ICU.

Data on the use of CPAP in COVID-19 patients treated outside ICU are scarce. Two (7\%) out of 28 patients received NIV or high-flow nasal cannula outside the ICU in a single-centre study in Wuhan [15]. ORANGER et al. [14] treated 38 patients with CPAP in a respiratory ward. Although the study included a limited number of patients, CPAP was feasible and the authors suggest a potential benefit for both full treatment and DNI patients, as opposed to those treated with oxygen only [14].

Regarding mortality concerns, we showed an overall cumulative 60-day in-hospital mortality of $34 \%$ in patients with moderate-to-severe forms of COVID-19-related ARF needing CPAP. The rate of mortality observed in our study is not divergent from those reported in several prior studies $[9,10,12,13,15]$ for ICU patients, predominantly intubated, which varied from $17 \%$ [13] to 67\% [9].

Lastly, our study includes 26\% DNI patients, for whom CPAP was considered the ceiling of treatment. The rate of DNI patients reported in our study is similar to the $15 \%$ observed in a small cohort of patients treated outside the ICU during the COVID-19 pandemic [14], as well as the $30 \%$ reported by a large Italian multicentre observational study in patients with non-COVID-19-related pneumonia treated with NIV outside the ICU [20]. In our study, 60-day in-hospital mortality for DNI patients was 73\%.

TABLE 3 Fine and Gray model for the association between noninvasive continuous positive airway pressure (CPAP) duration and mortality

$\operatorname{sHR}(95 \% \mathrm{CI})$

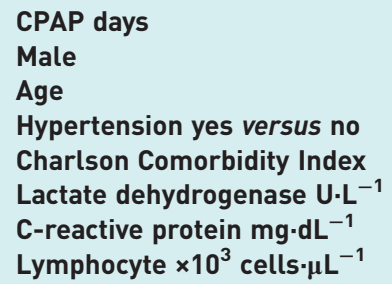


A major concern when treating patients with hypoxaemic ARF with NIV is related to NIV failure, which might occur in up $50 \%$ of the cases with consequent recourse to intubation [21]. Undue prolongation of NIV may worsen lung injury, resulting in so-called patient self-inflicted lung injury [22], while the direct consequence of NIV failure is delaying intubation and adequate treatment with invasive ventilation $[1,23]$. Our data confirm that intubation delay for those requiring later invasive ventilation is associated with increased risk of mortality. In other pandemics, such as influenza, $\mathrm{H} 1 \mathrm{~N} 1$ and severe acute respiratory syndrome, NIV failure ranges from $10 \%$ to $>70 \%$ [24], reaching $90 \%$ with Middle East respiratory syndrome [25]. In our study, the CPAP failure rate was $45 \%$, which indicates that effective treatment occurred in more than half of the patients, who avoided invasive ventilation through an endotracheal tube, a procedure which is life-saving, but prone to several side-effects and complications [26].

\section{Limitations}

The study has several limitations. First, we were not able to compare our population with an historical control. Second, most of the data have been retrospectively derived from the medical records. According to the retrospective nature of the study, formal criteria to start CPAP treatment were not defined a priori, and the time span between CPAP initiation and control ABG measurement was relatively long. Third, definitions of full treatment and DNI patients, although internationally accepted [6], are influenced by patients, families and clinicians, and might be influenced by cultural, religious and geographical factors. Fourth, due to the diversity of interfaces and devices used in our study, the actual applied pressure could somewhat differ from the pre-set value [27]. Fifth, due to the number of missing data among many important variables such as D-dimer and respiratory rate, we were not able introduce them into the model exploring the correlation between CPAP duration and mortality. Last, because of the exceptionality of the pandemic outbreak, our results are not generalisable to other conditions.

\section{Conclusions}

To the best of our knowledge, this is the largest retrospective cohort study on patients with COVID-19 treated with CPAP outside the ICU. We show that CPAP is feasible outside the ICU, with overall in-hospital mortality similar to that reported in other studies treating critically ill ICU patients. In-hospital mortality is closely related to the therapeutic goal; patients having a DNI order being affected by much higher mortality. Intubation delay is confirmed to be an independent risk factor for mortality. Further studies are necessary to ascertain the potential infective risk related to CPAP treatment outside ICU among healthcare workers.

Acknowledgements: We acknowledge all healthcare workers involved in the diagnosis and treatment of patients in the Eastern Piedmont region. We thank Davide Crimaldi (Università di Torino, Turin, Italy) for database support. The study received no funding. Preliminary data have been sent, in abstract form, to the European Society of Intensive Care Medicine Congress 2020.

Data availability: The data that support the findings of this study are available from the corresponding author, R. Vaschetto, upon reasonable request.

Conflict of interest: R. Vaschetto has nothing to disclose. F. Barone-Adesi has nothing to disclose. F. Racca reports personal fees from Philips Respironics outside the submitted work. C. Pissaia has nothing to disclose. C. Maestrone has nothing to disclose. D. Colombo reports personal fees for lectures from Nestlé Healthcare Nutrition outside the submitted work. C. Olivieri has a patent 102016000114357 with royalties paid to Intersurgical SpA. N. De Vita has nothing to disclose. E. Santangelo has nothing to disclose. L. Scotti has nothing to disclose. L. Castello has nothing to disclose. T. Cena has nothing to disclose. M. Taverna has nothing to disclose. L. Grillenzoni has nothing to disclose M.A. Moschella has nothing to disclose. G. Airoldi has nothing to disclose. S. Borrè has nothing to disclose. F. Mojoli reports personal fees for lecturing from GE Healthcare, Medical and Seda Spa, outside the submitted work; and a consultancy agreement between University of Pavia and Hamilton Medical. F. Della Corte has nothing to disclose. M. Baggiani has nothing to disclose. S. Baino has nothing to disclose. P. Balbo has nothing to disclose. S. Bazzano has nothing to disclose. V. Bonato has nothing to disclose. S. Carbonati has nothing to disclose. F. Crimaldi has nothing to disclose. V. Daffara has nothing to disclose. L. De Col has nothing to disclose. M. Maestrone has nothing to disclose. M. Malerba has nothing to disclose. F. Moroni has nothing to disclose. R. Perucca has nothing to disclose. M. Pirisi has nothing to disclose. V. Rondi has nothing to disclose. D. Rosalba has nothing to disclose. L. Vanni has nothing to disclose. F. Vigone has nothing to disclose. P. Navalesi reports personal fees from Intersurgical SpA, Resmed, Philips, Novartis, MSD, Getinge and Orion Pharma, and research equipment (institutional) from Draeger, outside the submitted work; in addition, he has a patent 102020000008305 pending to Università di Padova (no profit) and a patent 102016000114357 with royalties paid to Intersurgical SpA. G. Cammarota has nothing to disclose.

\section{Reference}

1 Rochwerg B, Brochard L, Elliott MW, et al. Official ERS/ATS clinical practice guidelines: noninvasive ventilation for acute respiratory failure. Eur Respir J 2017; 50: 1602426.

2 Masip J, Roque M, Sánchez B, et al. Noninvasive ventilation in acute cardiogenic pulmonary edema: systematic review and meta-analysis. JAMA 2005; 294: 3124-3130. 

among immunocompromised patients with acute respiratory failure: a randomized clinical trial. JAMA 2015; 314: $1711-1719$.

4 Jaber S, Lescot T, Futier E, et al. Effect of noninvasive ventilation on tracheal reintubation among patients with hypoxemic respiratory failure following abdominal surgery: a randomized clinical trial. JAMA 2016; 315: $1345-1353$.

5 Namendys-Silva SA, Hernández-Garay M, Rivero-Sigarroa E. Non-invasive ventilation for critically ill patients with pandemic H1N1 2009 influenza A virus infection. Crit Care 2010; 14: 407.

6 Curtis JR, Cook DJ, Sinuff T, et al. Noninvasive positive pressure ventilation in critical and palliative care settings: understanding the goals of therapy. Crit Care Med 2007; 35: 932-939.

7 Cabrini L, Moizo E, Nicelli E, et al. Noninvasive ventilation outside the intensive care unit from the patient point of view: a pilot study. Respir Care 2012; 57: 704-709.

8 Cabrini L, Esquinas A, Pasin L, et al. An international survey on noninvasive ventilation use for acute respiratory failure in general non-monitored wards. Respir Care 2015; 60: 586-592.

9 Arentz M, Yim E, Klaff L, et al. Characteristics and outcomes of 21 critically ill patients with COVID-19 in Washington State. JAMA 2020; 323: 1612-1614.

10 Grasselli G, Zangrillo A, Zanella A, et al. Baseline characteristics and outcomes of 1591 patients infected with SARS-CoV-2 admitted to ICUs of the Lombardy region, Italy. JAMA 2020; 323: 1574-1581.

11 Yang X, Yu Y, Xu J, et al. Clinical course and outcomes of critically ill patients with SARS-CoV-2 pneumonia in Wuhan, China: a single-centered, retrospective, observational study. Lancet Respir Med 2020; 8: 475-481.

12 Richardson S, Hirsch JS, Narasimhan M, et al. Presenting characteristics, comorbidities, and outcomes among 5700 patients hospitalized with COVID-19 in the New York City area. JAMA 2020; 323: 2052-2059.

13 Wang $\mathrm{D}, \mathrm{Hu}$ B, Hu C, et al. Clinical characteristics of 138 hospitalized patients with 2019 novel coronavirus-infected pneumonia in Wuhan, China. JAMA 2020; 323: 1061-1069.

14 Oranger M, Gonzalez-Bermejo J, Dacosta-Noble P, et al. Continuous positive airway pressure to avoid intubation in SARS-CoV-2 pneumonia: a two-period retrospective case-control study. Eur Respir J 2020; 56: 2001692.

15 Huang C, Wang Y, Li X, et al. Clinical features of patients infected with 2019 novel coronavirus in Wuhan, China. Lancet 2020; 395: 497-506.

16 Gristina GR, Orsi L, Carlucci A, et al. Parte I. Il percorso clinico e assistenziale nelle insufficienze croniche d'organo "end-stage". Documento di consenso per una pianificazione condivisa delle scelte di cura. [Part I. End-stage chronic organ failures: a position paper on shared care planning. The Integrated Care Pathway]. Recenti Prog Med 2014; 105: 9-24.

17 Charlson ME, Pompei P, Ales KL, et al. A new method of classifying prognostic comorbidity in longitudinal studies: development and validation. J Chronic Dis 1987; 40: 373-383.

18 Resche-Rigon M, Azoulay E, Chevret S. Evaluating mortality in intensive care units: contribution of competing risks analyses. Crit Care 2006; 10: R5.

19 Guan WJ, Ni ZY, Hu Y, et al. Clinical characteristics of coronavirus disease 2019 in China. N Engl J Med 2020; 382: $1708-1720$.

20 Brambilla AM, Prina E, Ferrari G, et al. Non-invasive positive pressure ventilation in pneumonia outside intensive care unit: an Italian multicenter observational study. Eur J Intern Med 2019; 59: 21-26.

21 Frat JP, Thille AW, Mercat A, et al. High-flow oxygen through nasal cannula in acute hypoxemic respiratory failure. N Engl J Med 2015; 372: 2185-2196.

22 Brochard L, Slutsky A, Pesenti A. Mechanical ventilation to minimize progression of lung injury in acute respiratory failure. Am J Respir Crit Care Med 2017; 195: 438-442.

23 Brochard L, Lefebvre JC, Cordioli RL, et al. Noninvasive ventilation for patients with hypoxemic acute respiratory failure. Semin Respir Crit Care Med 2014; 35: 492-500.

24 Esquinas AM, Egbert Pravinkumar S, Scala R, et al. Noninvasive mechanical ventilation in high-risk pulmonary infections: a clinical review. Eur Respir Rev 2014; 23: 427-438.

25 Alraddadi BM, Qushmaq I, Al-Hameed FM, et al. Noninvasive ventilation in critically ill patients with the Middle East respiratory syndrome. Influenza Other Respir Viruses 2019; 13: 382-390.

26 Esteban A, Frutos-Vivar F, Muriel A, et al. Evolution of mortality over time in patients receiving mechanical ventilation. Am J Respir Crit Care Med 2013; 188: 220-230.

27 Vargas F, Thille A, Lyazidi A, et al. Helmet with specific settings versus facemask for noninvasive ventilation. Crit Care Med 2009; 37: 1921-1928. 